\title{
Clinically mild encephalitis/encephalopathy with a reversible splenial lesion associated with febrile urinary tract infection
}

\author{
Takayuki Okamoto • Yasuyuki Sato • Takeshi Yamazaki • \\ Asako Hayashi
}

Received: 24 July 2013 / Accepted: 22 October 2013 /Published online: 13 November 2013

(C) The Author(s) 2013. This article is published with open access at Springerlink.com

\begin{abstract}
Common pathogens of clinically mild encephalitis/ encephalopathy with a reversible splenial lesion (MERS) are viruses, such as influenza virus. However, bacteria are rare pathogens for MERS. We report the first patient with MERS associated with febrile urinary tract infection. A 16-year-old lupus patient was admitted to our hospital. She had fever, headache, vomiting, and right back pain. Urinary analysis showed leukocyturia, and urinary culture identified Klebsiella pneumoniae. Cerebrospinal fluid examination and brain single-photon emission computed tomography showed no abnormalities. Therefore, she was diagnosed with febrile urinary tract infection. For further examinations, $99 \mathrm{mTc}-$ dimercaptosuccinic acid renal scintigraphy showed right cortical defects, and a voiding cystourethrogram demonstrated right vesicoureteral reflux (grade II). Therefore, she was diagnosed with right pyelonephritis. Although treatment with antibiotics administered intravenously improved the fever, laboratory findings, and right back pain, she had prolonged headaches, nausea, and vomiting. T2-weighted, diffusionweighted, and fluid attenuated inversion recovery images in brain magnetic resonance imaging showed high intensity lesions in the splenium of the corpus callosum, which completely disappeared 1 week later. These results were compatible with MERS. To the best of our knowledge, our patient is the first patient who showed clinical features of MERS associated with febrile urinary tract infection. Conclusion: In patients with pyelonephritis and an atypical clinical course, such as prolonged headache, nausea, vomiting, and neurological disorders, the possibility of MERS should be considered.
\end{abstract}

T. Okamoto $(\bowtie) \cdot$ Y. Sato $\cdot$ T. Yamazaki $\cdot$ A. Hayashi

Department of Pediatrics, Hokkaido University Graduate School of

Medicine, N15, W7, Sapporo 060-8638, Japan

e-mail: okamon@med.hokudai.ac.jp
Keywords Bacteria $\cdot$ Febrile urinary tract infection $\cdot$ MERS · Pyelonephritis $\cdot$ Systemic lupus erythematosus

\author{
List of abbreviations \\ MERS clinically mild encephalitis/encephalopathy with a \\ reversible splenial lesion \\ MRI magnetic resonance imaging \\ SLE systemic lupus erythematosus \\ CSF cerebrospinal fluid \\ VCUG voiding cystourethrogram \\ DMSA dimercaptosuccinic acid \\ IL interleukin
}

\section{Introduction}

Clinically mild encephalitis/encephalopathy with a reversible splenial lesion (MERS) is characterized by magnetic resonance imaging (MRI) of a reversible isolated lesion with transiently reduced diffusion in the splenium of the corpus callosum [10]. The most common clinical manifestation is a neurological disorder, such as delirious behavior, consciousness disturbance, and seizures. Most patients with MERS clinically recover completely within 1 month [11]. Influenza virus types $\mathrm{A}$ and $\mathrm{B}$ are the most common pathogens of MERS. However, bacterial infection has also been reported as pathogens in a few patients with MERS and not in patients with other classifications of acute encephalopathy, such as acute necrotizing encephalopathy and acute encephalopathy with biphasic seizures and late reduced diffusion [5]. We report here the first patient with MERS associated with febrile urinary tract infection. 
Fig. 1 MRI findings of a 16-year-old girl with MERS associated with a febrile urinary tract infection. a On the third hospital day, a high signal lesion was observed in the splenium of the corpus callosum as shown by FLAIR MRI (white arrows). b On the tenth hospital day, the splenial lesion had completely disappeared. FLAIR fluid attenuated inversion recovery, $M R I$ magnetic resonance imaging, MERS clinically mild encephalitis/encephalopathy with a reversible splenial lesion
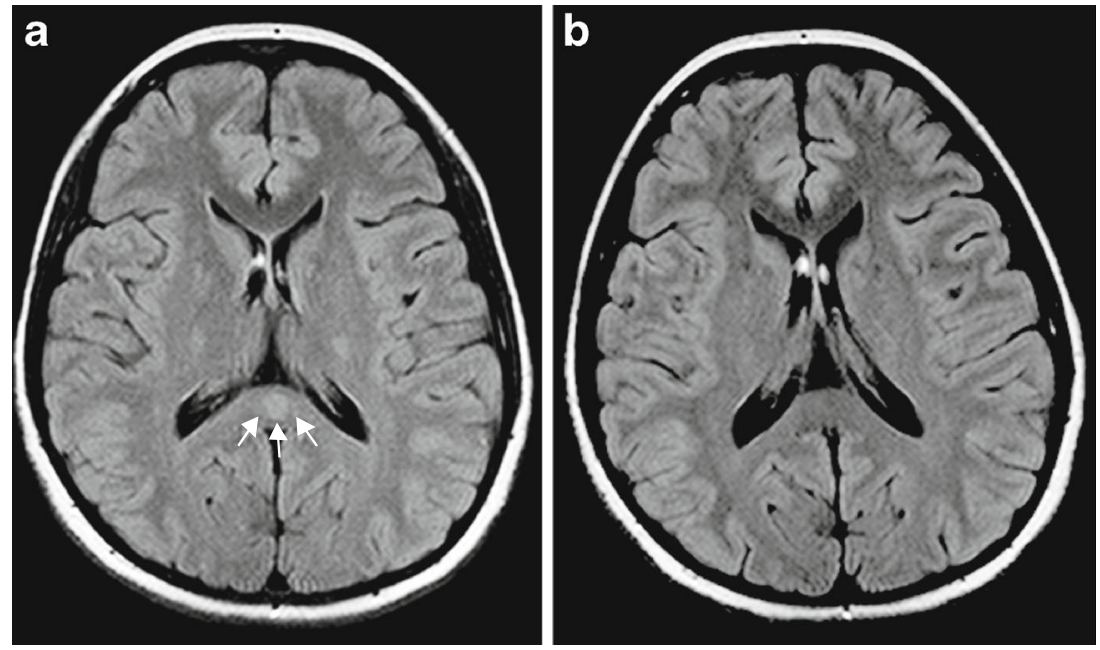

\section{Case report}

A 15-year-old Japanese girl was admitted to the hospital with severe periorbital and pedal edema. She also had a butterfly shadow, oral ulcer, and joint pain. A peripheral blood examination showed thrombocytopenia (platelets, $66 \times 10^{9} / 1$ ), hypoproteinemia (serum total protein, $33 \mathrm{~g} /$ ), hypoalbuminemia (serum albumin, $6 \mathrm{~g} / \mathrm{l}$ ), and hypercholesterolemia (total cholesterol, $13 \mathrm{mmol} / \mathrm{l})$. Her serum creatinine level was normal $(41.5 \mu \mathrm{mol} / \mathrm{l})$. Immunological studies were positive for antinuclear antibody with a titer of 1:640 in a peripheral pattern, anti-smooth muscle antibody of $0.22 \mathrm{U} / 1$ (normal range, 0.0 $0.0059 \mathrm{U} / \mathrm{l}$ ), anti-U1 ribonucleic protein antibody of $0.15 \mathrm{U} / 1$ (normal range, $0.0-0.012 \mathrm{U} / \mathrm{l}$ ), and anti-single-stranded DNA antibody of $0.035 \mathrm{U} / \mathrm{l}$ (normal range, $0-0.025 \mathrm{U} / \mathrm{l})$. Serum complement levels were low, with $\mathrm{C} 3$ of $0.49 \mathrm{~g} / 1$ (normal range, 0.86-1.6 g/l), C4 of 0.1 g/l (normal range, 0.17-0.45 g/l), and CH50 of $22.3 \mathrm{kU} / \mathrm{l}$ (normal range, 31.5-48.4 kU/1). Sediment contained 20-29 red blood cells and cellular casts per highpower field, and urinalysis showed proteinuria at a concentration of $34,010 \mathrm{~g} / 1$ and urinary protein to creatinine ratio of $27 \mathrm{~g} / \mathrm{gCr}$. Based on these findings, she was diagnosed with systemic lupus erythematosus (SLE) with nephrotic syndrome. Renal biopsy findings showed a minor glomerular abnormality under light microscopy. By immunofluorescence study, granular depositions of $\operatorname{IgG}$ and $\mathrm{C} 3$ along the peripheral capillaries were observed, and electron microscopy showed subepithelial deposits. With prednisolone and tacrolimus, she achieved complete remission after 8 months.

At the age of 16 years, the patient had fever, headache, vomiting, and right back pain. One day later, she had chills and delirious behavior followed by consciousness disturbance. On admission, the patient was awake but appeared severely ill owing to malaise and dehydration. Her blood pressure was $87 /$ $45 \mathrm{mmHg}$, pulse was 89 beats per minute, temperature was $39.5^{\circ} \mathrm{C}$, and oxygen saturation was $98 \%$ while she was breathing ambient air. Her abdominal pain was localized to the right back region, and costovertebral angle tenderness was positive. Peripheral blood analysis showed leukocytosis (white blood cell count, $\left.18 \times 10^{9} / 1\right)$, an elevated C-reactive protein level of $0.17 \mathrm{~g} / \mathrm{l}$ (normal range, 0.0-0.0039 g/l), and serum creatinine level of $78.6 \mu \mathrm{mol} / \mathrm{l}$. Complement levels were normal. Urinary sediments contained 10-19 white cells, and urinary culture was positive for Klebsiella pneumoniae. Cerebrospinal fluid (CSF) examination showed no abnormalities, and cultures of blood and CSF were negative. In addition, brain single-photon emission computed
Table 1 Pathogens of clinically mild encephalitis/encephalopathy with a reversible splenial lesion (MERS) in the literature

\begin{tabular}{|c|c|c|}
\hline Authors & $\begin{array}{l}\text { No. of } \\
\text { patients }\end{array}$ & Pathogens of MERS in the literature (no. of patients) \\
\hline Hoshino et al. [5] & 153 & $\begin{array}{l}\text { Influenza (53), rotavirus (18), mumps virus (6), HHV-6 (3), } \\
\text { bacterial infection (5) }\end{array}$ \\
\hline Takanashi et al. [11] & 54 & $\begin{array}{l}\text { Unknown (22), influenza A/B (6/4), mumps virus (4), adenovirus (3), } \\
\text { rotavirus (3), streptococcus (3), Escherichia coli (3) }\end{array}$ \\
\hline Tada et al. [10] & 15 & $\begin{array}{l}\text { Unknown (10), influenza A (1), adenovirus (1), mumps virus (1), } \\
\text { VZV virus (1) }\end{array}$ \\
\hline Bulakbasi et al. [1] & 5 & Influenza A (5) \\
\hline Ganapathy et al. [3] & 2 & Influenza B (2) \\
\hline Takanashi et al. [13] & 4 & Kawasaki disease (4) \\
\hline
\end{tabular}


tomography showed no abnormalities. Therefore, it was thought that flaring of lupus was unlikely, and she was diagnosed with febrile urinary tract infection. Further examinations, including a voiding cystourethrogram (VCUG) and $99 \mathrm{mTc}-$ dimercaptosuccinic acid (DMSA) renal scintigraphy, were performed. VCUG showed right vesicoureteral reflux (grade II), and 99mTc-DMSA scintigraphy showed right cortical defects. These results were compatible with right pyelonephritis. Thereafter, treatment with intravenous antibiotics gradually improved signs and symptoms, such as fever, laboratory findings, and right back pain, but she had prolonged headaches, nausea, and vomiting. Therefore, further examinations were performed. As a result, T2weighted, diffusion-weighted, and fluid attenuated inversion recovery images in brain MRI showed high intensity lesions in the splenium of the corpus callosum on the third hospital day, which completely disappeared 1 week later (Fig. 1). At the same time, headaches, nausea, and vomiting also gradually improved. These typical findings of MRI and clinical features were compatible with MERS.

At the age of 17 years, the patient has not had recurrence of MERS with sustained remission of lupus.

\section{Discussion}

To the best of our knowledge, our patient is the first patient who showed clinical features of MERS associated with a febrile urinary tract infection. Furthermore, this report is also the first to show an association between MERS and K.pneumonia infection. The major pathogens of MERS are viruses, such as influenza virus ( $\mathrm{A}$ and $\mathrm{B})$, mumps virus, adenovirus, and rotavirus (Table 1). However, bacteria are also known as pathogens, which account for $3.3 \%$ of all causes of MERS [5]. Streptococci and Escherichia coli have been reported as bacterial pathogens of MERS [11]. Because bacterial pathogens have not been identified in acute necrotizing encephalopathy and acute encephalopathy with biphasic seizures and late reduced diffusion cases, further research on bacterial pathogens of MERS is required for understanding the etiology and pathogenesis of MERS.

About the pathogenesis of MERS, there are several hypotheses such as intramyelinic edema, hyponatremia, axonal damage, and oxidative stress $[6,8,10,12]$. However, the exact reason for the development of MERS in patients with bacterial infection, as well as our patient, is unknown. Serum proinflammatory cytokines, including interleukin (IL)-1 $\beta$, IL-6, and IL-8, and tumor necrosis factor-alpha are elevated in patients with acute pyelonephritis [4, 9], and Kawasaki disease, by which MERS is also complicated [13]. Therefore, activation of the immune system is likely to be associated with the pathogenesis of MERS. Although our patient did not appear to have flaring of lupus, lupus was possibly associated with the pathogenesis of MERS in our patient because the pathogenesis of SLE also appears to be associated with activation of the immune system and oxidative stress [2, 14].

Because of the prolonged headaches, nausea, and vomiting, further examinations were carried out following detection of MERS in our patient. In patients with acute pyelonephritis, clinical findings included varied gastrointestinal signs and symptoms, such as diarrhea, vomiting, and nausea [7]. Furthermore, neurological manifestations, such as irritability and seizures, are also possible clinical findings in pyelonephritis [7]. Therefore, at the onset, it is difficult to determine whether there are typical clinical findings in pyelonephritis or complications of MERS in patients with pyelonephritis. However, if gastrointestinal and neurological features are prolonged after improving pyelonephritis, clinicians should consider the possibility of MERS.

Acknowledgments We would like to thank Dr. Kohsuke Kudo and Dr. Hideaki Shiraishi for their contribution to diagnosis and management of our patient.

Conflict of interest The authors declare no conflict of interest.

Open Access This article is distributed under the terms of the Creative Commons Attribution License which permits any use, distribution, and reproduction in any medium, provided the original author(s) and the source are credited.

\section{References}

1. Bulakbasi N, Kocaoglu M, Tayfun C, Ucoz T (2006) Transient splenial lesion of the corpus callosum in clinically mild influenzaassociated encephalitis/encephalopathy. AJNR Am J Neuroradiol 27(9):1983-1986

2. Choi J, Kim ST, Craft J (2012) The pathogenesis of systemic lupus erythematosus - an update. Curr Opin Immunol 24(6):651-657. doi: 10.1016/j.coi.2012.10.004

3. Ganapathy S, Ey EH, Wolfson BJ, Khan N (2008) Transient isolated lesion of the splenium associated with clinically mild influenza encephalitis. Pediatr Radiol 38(11):1243-1245

4. Gurgoze MK, Akarsu S, Yilmaz E, Godekmerdan A, Akca Z, Ciftci I, Aygun AD (2005) Proinflammatory cytokines and procalcitonin in children with acute pyelonephritis. Pediatr Nephrol 20(10):1445 1448. doi:10.1007/s00467-005-1941-6

5. Hoshino A, Saitoh M, Oka A, Okumura A, Kubota M, Saito Y, Takanashi J, Hirose S, Yamagata T, Yamanouchi H, Mizuguchi M (2012) Epidemiology of acute encephalopathy in Japan, with emphasis on the association of viruses and syndromes. Brain Dev 34(5): 337-343. doi:10.1016/j.braindev.2011.07.012

6. Miyata R, Tanuma N, Hayashi M, Imamura T, Takanashi J, Nagata R, Okumura A, Kashii H, Tomita S, Kumada S, Kubota M (2012) Oxidative stress in patients with clinically mild encephalitis/encephalopathy with a reversible splenial lesion (MERS). Brain Dev 34(2):124-127. doi:10.1016/j.braindev.2011. 04.004

7. Practice parameter: the diagnosis, treatment, and evaluation of the initial urinary tract infection in febrile infants and young children. American Academy of Pediatrics. Committee on Quality Improvement. Subcommittee on Urinary Tract Infection (1999). Pediatrics 103 (4 Pt 1):843-852 
8. Prilipko O, Delavelle J, Lazeyras F, Seeck M (2005) Reversible cytotoxic edema in the splenium of the corpus callosum related to antiepileptic treatment: report of two cases and literature review. Epilepsia 46(10):1633-1636. doi:10.1111/j. 1528-1167.2005.00256.x

9. Sheu JN, Chen MC, Lue KH, Cheng SL, Lee IC, Chen SM, Tsay GJ (2006) Serum and urine levels of interleukin-6 and interleukin-8 in children with acute pyelonephritis. Cytokine 36(5-6):276-282. doi: 10.1016/j.cyto.2007.02.006

10. Tada H, Takanashi J, Barkovich AJ, Oba H, Maeda M, Tsukahara H, Suzuki M, Yamamoto T, Shimono T, Ichiyama T, Taoka T, Sohma O, Yoshikawa H, Kohno Y (2004) Clinically mild encephalitis/ encephalopathy with a reversible splenial lesion. Neurology 63(10): 1854-1858
11. Takanashi J (2009) Two newly proposed infectious encephalitis/ encephalopathy syndromes. Brain Dev 31(7):521-528. doi:10. 1016/j.braindev.2009.02.012

12. Takanashi J, Maeda M, Hayashi M (2005) Neonate showing reversible splenial lesion. Arch Neurol 62(9):1481-1482. doi:10.1001/ archneur.62.9.1481, author reply 1482

13. Takanashi J, Shirai K, Sugawara Y, Okamoto Y, Obonai T, Terada H (2012) Kawasaki disease complicated by mild encephalopathy with a reversible splenial lesion (MERS). J Neurol Sci 315(1-2):167-169. doi:10.1016/j.jns.2011.11.022

14. Wang G, Pierangeli SS, Papalardo E, Ansari GA, Khan MF (2010) Markers of oxidative and nitrosative stress in systemic lupus erythematosus: correlation with disease activity. Arthritis Rheum 62(7): 2064-2072. doi:10.1002/art.27442 